\title{
Management of osteoarthritis of the knee in younger patients
}

\author{
Moin Khan MD MSc, Anthony Adili MD, Mitchell Winemaker MD, Mohit Bhandari MD PhD
}

Cite as: CMAJ 2018 January 22;190:E72-9. doi: 10.1503/cmaj.170696

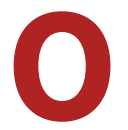

steoarthritis has a high global health and economic burden and will become the fourth leading cause of disability by the year 2020, according to data from the World Health Organization. ${ }^{1}$ Official Canadian statistics estimate that 1 in 10 Canadians aged 15 years or older suffers from osteoarthritis and prevalence increases with age. ${ }^{2}$ Symptomatic osteoarthritis most commonly affects the knee; $29 \%$ of all Canadian cases of osteoarthritis involve the knee. As the population ages and rates of obesity rise, it is estimated that the number of individuals affected will increase to one in five by 2031. A recent study estimated that loss of productivity from chronic pain and loss of mobility owing to the disease costs the Canadian economy $\$ 17.5$ billion annually. ${ }^{3}$

Total knee replacement represents the definitive treatment for disabling knee osteoarthritis that has not responded to nonoperative treatments, which include analgesics, weight loss, bracing, modification of activity, physiotherapy and intraarticular injections. However, this treatment is not always advisable, particularly in young patients. Treating young patients who have pain and functional limitation owing to knee involvement is a clinical challenge; these patients have been referred to as falling into a "treatment gap," as they are too young or may be unwilling to undergo total knee replacement. ${ }^{4}$ Available clinical practice guidelines vary substantially in both their quality and specific treatment recommendations for younger patients with osteoarthritis (Box 1$)^{5}$

\section{Box 1: Evidence used in this review}

A single reviewer (MK) searched PubMed, MEDLINE, Embase and Cochrane databases with combinations of the terms "knee" and "osteoarthritis," using the "related articles" function. The search was restricted to research published over the last 10 years (Apr. 1, 2007 to Mar. 31, 2017).

Articles were screened for relevance and attention was focused on recently published research, including systematic reviews, meta-analyses and randomized controlled trials. Inclusion criteria involved all clinical articles related to knee osteoarthritis. We excluded all basic science studies, case series and case reports, as well as those studies that reported on osteoarthritis involving joints other than the knee.

\section{KEY POINTS}

- Conservative treatment for knee osteoarthritis includes weight loss, modification of activity, nonsteroidal anti-inflammatory drugs, physical therapy and bracing, in select cases; this should form the initial treatment approach.

- Knee injectables including hyaluronic acid, cortisone, plateletrich plasma and combination therapies may provide effective symptom relief, and the placebo effect of intra-articular injection has been shown to exceed that of nonsteroidal antiinflammatory drugs.

- Arthroscopic management of osteoarthritic symptoms by means of arthroscopic lavage or arthroscopic debridement has been shown to have no benefit, in several high-quality randomized controlled trials.

- The effect of acetominophen has been shown to be negligible; pharmaceutical-grade (but not nutraceutical-grade) chondroitin sulphate may offer some benefit for pain relief; commonly used treatments such as acupuncture, taping, shoe wedges and transcutaneous electrical nerve conduction are not supported by evidence.

- Surgical and arthroplasty options, which have been shown to be effective, should be delayed as long as possible, after all possible nonoperative treatments have been exhausted.

We review evidence for both nonoperative and surgical treatment options that are available for young patients with primary knee osteoarthritis, focusing on high-quality clinical research including systematic reviews, meta-analyses and randomized controlled trials (RCTs) - and guidelines published in the last decade (Box 1). We discuss conflicting treatment guidelines and provide an update on emerging treatments and ongoing research.

\section{Why the "treatment gap" for younger patients?}

The relatively young and active individual with osteoarthritis presents a challenging clinical scenario for several reasons. Such patients often seek to remain involved in sporting activities. However, as degenerative changes involving the cartilage and meniscus progress, nonoperative treatment options are often 
exhausted relatively quickly. The time between exhaustion of nonoperative treatment options and definitive surgical management has been described in the literature as a treatment gap. ${ }^{4}$ Those who fall into the gap are frequently younger than 60 years with early- to midstage knee osteoarthritis (Kellgren and Lawrence grade 1-3), yet may include any individual who is symptomatic and for whom nonoperative management is no longer effective. ${ }^{6}$ Such patients make up about $20 \%$ of all those affected by knee osteoarthritis, which has been estimated as 3.6 million Americans and projected to increase to 5 million by $2025 .{ }^{4} \mathrm{~A}$ recent small survey of orthopedic surgeons found that $84 \%$ perceived a need for improved treatment options for patients younger than 60 years who have osteoarthritis, and $68.4 \%$ of surgeons perceived that there is a treatment gap for these patients. ${ }^{6}$

The treatment gap exists because many nonoperative treatment options and minimally invasive surgical procedures are ineffective in long-term management of osteoarthritic symptoms. Invasive procedures such as knee arthroplasty do not meet patient expectations for continued highly active lifestyles and patients are unwilling to deal with subsequent revision arthroplasty procedures, which may be inevitable.,

Despite technological advances, many patients are not satisfied with their total knee replacement. A cross-sectional study of 1703 primary total knee replacements in the province of Ontario confirmed that almost one in five (19\%) of patients were not satisfied with the outcome. ${ }^{9}$ The study identified that younger patients ( $<70 \mathrm{yr}$ ) were more likely to be dissatisfied with the total knee replacement compared with those who were older at the time of the procedure. ${ }^{9}$ Similarly, a multicentre survey of 661 patients younger than 60 years who underwent total knee replacement found that many reported residual pain (33\%) and stiffness (41\%), and 50\% were unable to return to desired sport or recreational activity. ${ }^{10}$ Recent research shows that total knee replacement is cost-effective only when performed on those with substantial functional limitations. ${ }^{11}$

Despite this, studies from the United Kingdom have found that $15 \%$ of all total knee replacement procedures are performed in patients younger than 60 years, and project a future increase..$^{12,13}$ The increased risk of revision surgery in the younger population a function of both implant longevity and increased level of activity, resulting in increased mechanical wear - heralds a particular problem with a growing need for revision surgery. A recent, large, population-based study examining 54276 total knee replacements found the lowest implant survival rates in patients who were in their 50s at the time of index surgery. ${ }^{14}$ Younger men between the ages of 50 and 54 had a lifetime risk of revision total knee replacement of $35.0 \%$ compared with $4.4 \%$ for those aged 70 years at time of surgery. ${ }^{14}$ Quality of life and satisfaction of patients living with revision implants are much lower than for those living with primary total knee replacement. ${ }^{15}$

\section{Which noninvasive treatments may be used for knee osteoarthritis?}

Evidence-based, nonsurgical options available for managing knee osteoarthritis in both the young and older populations range from lifestyle modification and medications, to more invasive injectable therapies, some of which can be begun by primary care physicians.

\section{Weight loss}

Weight loss leads to a reduced load of forces across the knee joint and, along with exercise, may improve biomechanics and physical function. Biomechanical studies show that $1 \mathrm{~kg}$ of weight loss correlates to a fourfold decrease in forces across the knee. ${ }^{16}$ Frequently, weight loss alone will relieve symptoms for patients with osteoarthritic symptoms. A systematic review and meta-analysis of 44 RCTs comparing land-based exercise programs to no exercise found that exercise reduced pain burden (12 points/100, 95\% confidence interval [ $\mathrm{Cl}] 10$ to 15 ), improved quality of life and improved physical function (10 points/100, $95 \% \mathrm{Cl} 8$ to 13$).{ }^{17}$ Both diet and exercise interventions have been shown to facilitate weight loss. A large RCT showed weight loss of $4.9 \%$ total body weight for diet-only intervention versus $5.7 \%$ diet-plus-exercise intervention over an 18-month period ${ }^{18}$ among people with arthritis. Low-impact aerobic exercise (swimming or elliptical training) promotes weight loss and cardiovascular health while preserving injured joint surfaces..$^{17,19}$

\section{Bracing}

Knee osteoarthritis most frequently involves the medial aspect of the knee joint. Numerous studies have been published on the efficacy of unloader bracing in knee osteoarthritis, and although a recent scoping review identified that $92 \%$ of studies supported their use, $94 \%$ of available research was nonrandomized or based upon expert opinion. ${ }^{20} \mathrm{~A}$ meta-analysis of six RCTs comparing the use of a medial unloader knee brace for the treatment of medial compartment arthritis to a control orthosis found a small, statistically significant benefit favouring the brace for improvement in pain (standardized mean difference [SMD] 0.33, 95\% $\mathrm{Cl} 0.13$ to 0.52 ) and function (SMD $0.22,95 \% \mathrm{Cl} 0.02$ to 0.41 ). ${ }^{21}$ Because of the low quality of available evidence, the clinical importance of these findings remains unclear.

\section{Physical therapy and quadriceps strengthening}

Strengthening exercises and physical therapy work to strengthen the leg muscles, particularly the quadriceps, to reduce load and direct knee joint stress during movement. ${ }^{22}$ A systematic review of 26 RCTs that evaluated various strengthening exercise programs in the setting of knee osteoarthritis found moderate improvements in pain, physical function and quality of life. ${ }^{23}$

\section{Oral and topical nonsteroidal anti-inflammatory medications}

Nonsteroidal anti-inflammatory medications taken orally are the most commonly prescribed treatment for osteoarthritis, prescribed to $65 \%$ of patients with osteoarthritis in the United States. ${ }^{24} \mathrm{~A}$ recent network meta-analysis assessed the effectiveness of different preparations and doses of nonsteroidal anti-inflammatory drugs for osteoarthritis pain from 74 RCTs and identified diclofenac $150 \mathrm{mg} /$ day to be the most efficacious in terms of relieving pain and improving physical function. ${ }^{25}$ However, nonsteroidal anti- 
inflammatory drugs taken orally have potentially important gastrointestinal, renal and cardiovascular risks. Daily nonsteroidal antiinflammatory drug use has been associated with a fourfold increase in the risk of upper gastrointestinal bleeding, and a metaanalysis of 280 RCTs identified an increase in major vascular events by one-third with the use of a COX-2 inhibitor. ${ }^{26,27}$

Topical nonsteroidal anti-inflammatory drugs are commonly used for the treatment of osteoarthritic pain because of their lower-risk profile compared with oral formulations. ${ }^{28}$ Numerous guidelines support use of topical agents and meta-analyses and systematic reviews have shown that topical diclofenac and ketoprofen are beneficial for those with knee osteoarthritis. ${ }^{28-30} \mathrm{~A}$ review of comparative studies found no statistically significant differences in the efficacy of topical and oral formulations. ${ }^{31}$ Reported adverse effects are rare, with the most commonly reported a mild skin reaction. ${ }^{30}$ Given the reported efficacy of topical agents, we suggest using topical agents initially before beginning oral agents, given the difference in safety concerns.

\section{Oral opioid medications}

There are concerns regarding the safety and effectiveness of opioid medication taken orally. A recent systematic review showed that nonsteroidal anti-inflammatory drugs and opioids provided similar pain relief for patients with osteoarthritis. ${ }^{32}$ Published clinical practice guidelines vary in their recommendations; we suggest that given their potential adverse effects, opioids should not be used as a first-line treatment option for patients with osteoarthritis (Table 1). If opioid medications are used, we suggest following a recent Canadian guideline and recommendations. ${ }^{39}$

\section{Which injectable therapies may be used?}

Commonly used intra-articular therapies include viscosupplementation, corticosteroids or combination therapies. ${ }^{40}$

\section{Viscosupplementation}

Basic science research has shown that knees affected by osteoarthritis are deficient in hyaluronic acid, a naturally occurring polysaccharide within synovial fluid, which acts as a viscoelastic shock absorber. ${ }^{41}$ Viscosupplementation aims to restore the viscoelastic properties of synovial fluid and contains antiinflammatory and chondroprotective properties. ${ }^{42}$ Many formulations are available and vary with regard to molecular weight (low or high formulations), method of production (avianderived or synthetic), cost and dosing (multiple or single intraarticular injection). ${ }^{42}$ While a Cochrane systematic review of 76 RCTs found improvements in knee pain and function for viscosupplementation in comparison with placebo, several other meta-analyses have produced conflicting results. ${ }^{33,43,44}$ Available data from RCTs have had small sample sizes and been methodologically poor. ${ }^{33}$ Recent evidence from a meta-analysis of 68 RCTs suggests that high-molecular-weight formulations (> $3000 \mathrm{kDa}$ ) show both statistically significant and clinically important thresholds of efficacy with pain relief as well as an improved safety profile. ${ }^{45}$

Table 1: Current clinical practice guideline recommendations for treating knee osteoarthritis ${ }^{33}$

\begin{tabular}{|c|c|c|c|c|c|}
\hline Intervention & EULAR $^{34}$ & $\mathrm{ACR}^{35}$ & $\mathrm{AAOS}^{36}$ & NICE $^{37}$ & OARSI $^{38}$ \\
\hline Acetaminophen & $\begin{array}{l}\text { Beneficial in some } \\
\text { instances }\end{array}$ & $\begin{array}{l}\text { Beneficial in some } \\
\text { instances }\end{array}$ & Uncertain & Recommend & Recommend \\
\hline Oral NSAIDs & $\begin{array}{l}\text { Beneficial in some } \\
\text { instances }\end{array}$ & $\begin{array}{l}\text { Beneficial in some } \\
\text { instances }\end{array}$ & Recommend & Recommend & Recommend \\
\hline Topical NSAIDs & $\begin{array}{l}\text { Beneficial in some } \\
\text { instances }\end{array}$ & $\begin{array}{l}\text { Beneficial in some } \\
\text { instances }\end{array}$ & Recommend & Recommend & Recommend \\
\hline Opioids & $\begin{array}{l}\text { Beneficial in some } \\
\text { instances }\end{array}$ & Uncertain & Uncertain & Uncertain & Uncertain \\
\hline $\begin{array}{l}\text { Intra-articular } \\
\text { corticosteroids }\end{array}$ & $\begin{array}{l}\text { Beneficial in some } \\
\text { instances }\end{array}$ & $\begin{array}{l}\text { Beneficial in some } \\
\text { instances }\end{array}$ & Uncertain & Recommend & Recommend \\
\hline $\begin{array}{l}\text { Intra-articular } \\
\text { hyaluronic acid }\end{array}$ & $\begin{array}{l}\text { Beneficial in some } \\
\text { instances }\end{array}$ & Uncertain & Not recommended & Not recommended & Uncertain \\
\hline Acupuncture & $\begin{array}{l}\text { Beneficial in some } \\
\text { instances }\end{array}$ & $\begin{array}{l}\text { Beneficial in some } \\
\text { instances }\end{array}$ & Not recommended & Not recommended & Uncertain \\
\hline $\begin{array}{l}\text { Glucosamine or } \\
\text { chondroitin }\end{array}$ & $\begin{array}{l}\text { Beneficial in some } \\
\text { instances }\end{array}$ & Not recommended & Not recommended & Not recommended & Uncertain \\
\hline Bracing* & Recommend & Uncertain & Uncertain & $\begin{array}{l}\text { Beneficial in some } \\
\text { instances }\end{array}$ & Recommend \\
\hline Arthroscopic lavage & Not recommended & Not recommended & Not recommended & Not recommended & Not recommended \\
\hline
\end{tabular}




\section{Corticosteroids}

Corticosteroid anti-inflammatory drugs are commonly used to treat symptoms of knee osteoarthritis. A 2015 Cochrane systematic review concluded that intra-articular corticosteroid injection results in short-term improvement in pain $(<6 \mathrm{mo})$ with effects decreasing over time..$^{46}$ These findings were corroborated in research in 2016 that found intra-articular cortisone injection reduced pain more than sham or no intervention (SMD $-0.40,95 \% \mathrm{Cl}-0.58$ to -0.22 ). Available studies are of low quality, however, with substantial heterogeneity among trials. ${ }^{47}$ The long-term use of intra-articular cortisone has also been brought into question with the finding from a recent wellconducted RCT that found that repeated (four times per year over two years) intra-articular injection of $40 \mathrm{mg}$ of corticosteroids results in greater cartilage volume loss than in patients receiving a saline control injection..$^{48}$ Owing to these findings, we suggest that intra-articular cortisone be used infrequently for symptomatic control of arthritis.

\section{Combination therapies}

Combination therapies involve simultaneous injection of more than one therapy for improved pain control through their synergistic effect. Commonly used combination therapies include intra-articular corticosteroid and hyaluronic acid. An RCT comparing hyaluronic acid with a combination therapy including triamcinolone hexacetonide showed earlier onset of pain relief with the combination formulation. ${ }^{40}$ Platelet-rich plasma and hyaluronic acid combinations are now being used, with early clinical results suggesting decreased pain and functional limitations compared with platelet-rich plasma or hyaluronic acid alone. ${ }^{49,50}$

\section{What surgical treatments are effective?}

Realignment procedures or arthroplasty are the primary surgical treatments for patients with disabling symptoms of osteoarthritis not adequately controlled with nonoperative treatment.

\section{Tibial osteotomy}

Knee realignment procedures may allow for arthroplasty to be avoided or delayed; usually allow for continued high level of activity; and can preserve native joint mechanics. In cases where osteoarthritic changes are isolated to the medial or lateral compartment of the knee, the most common is high tibial osteotomy on one side to offload the diseased compartment. A Cochrane systematic review that evaluated 21 RCTs comparing osteotomy with other treatments for patients with unicompartmental osteoarthritis concluded that such procedures improved pain and function, although available evidence was of limited quality. ${ }^{51}$ A study using Finnish registry data of 3195 procedures done between 1987 and 2008 showed overall joint survivorship of $89 \%$ (95\% Cl 88 to 90 ) at five years and $73 \%$ (95\% Cl 72 to 75 ) at 10 years. ${ }^{52}$ Survivorship was found to be increased in patients younger than 50 years (hazard ratio [HR] $1.41,95 \% \mathrm{Cl} 1.23$ to 1.64 ) compared with those older than 50 (HR 1.26, $95 \% \mathrm{Cl} 1.11$ to 1.43 ). ${ }^{52}$ Although there is concern regarding increased complexity of total knee replacement following high tibial osteotomy, meta-analysis of published data suggests no differences in functional outcomes, survivorship or complication rates when total knee replacement is performed in those with or without previous high tibial osteotomy..$^{33}$

\section{Unicompartmental knee arthroplasty}

In cases of monocompartmental osteoarthritis - that is, where only one joint surface is involved - unicompartmental knee arthroplasty may allow for native joint mechanics to be conserved better than with total knee replacement in selected patients. Consideration has to be given to increased risk of revision in the younger patient, as registry data from Australia and Sweden show that patients younger than 55 years are at significantly higher risk. ${ }^{54}$ In the literature, estimated survival for unicompartmental knee arthroplasty is reported to be $93 \%$ at 10 years and $89 \%$ at 15 years. ${ }^{55}$ Return to sport and physical activity is higher with unicompartmental knee arthroplasty than with total knee replacement, with reported rates in the literature from $36 \%$ to $89 \%$ after total knee replacement and from $75 \%$ to $>100 \%$ (i.e., that more patients participated in sports postoperatively than preoperatively) after unicompartmental knee arthroplasty. ${ }^{56}$ Results of total knee replacement following unicompartmental knee arthroplasty in the literature are slightly poorer than primary total knee arthroplasty. ${ }^{57}$

\section{Total knee replacement}

Total knee replacement is often the definitive treatment for end-stage osteoarthritis after nonoperative treatment has been exhausted, and recent high-quality evidence has shown that total knee replacement is effective in reducing pain and improving function..$^{58}$ Increasingly, total knee replacement is being done in patients younger than 60 years. Implant survival is affected by patient factors such as activity level, bone quality and age, as well as implant factors such as bearing surfaces and fixation method. ${ }^{59}$ Although cementless techniques have been proposed along with alternative bearings surfaces, no high-quality randomized studies have yet shown the improvements of such techniques over current arthroplasty methods..$^{60}$

\section{What treatments are not supported by evidence?}

For some treatments, available evidence shows no effect, or even harm.

Across most guidelines, nutritional supplements, including glucosamine and chondroitin, which were thought to be promising, are either not recommended, or it is acknowledged that the evidence supporting their use is not sufficient to make recommendations (Table 1 ). However, a recent RCT evaluating $800 \mathrm{mg} /$ day pharmaceutical-grade chondroitin sulphate compared with celecoxib and placebo in more than 600 patients found chondroitin to be similar to 
celecoxib and superior to placebo in reducing pain and improving function, with low risk for adverse events. ${ }^{61}$ Nutraceutical-grade chondroitin, however, has been shown to be ineffective in numerous studies, likely owing to variations in preparation, composition and purity. Primary care physicians may consider the use of oral pharmaceutical-grade chondroitin sulphate in the treatment of knee osteoarthritis.

Acupuncture, transcutaneous electrical nerve conduction, knee tape, ${ }^{62}$ lateral wedge insoles ${ }^{63}$ and naturopathic or homeopathy alternatives are commonly used nonpharmacologic approaches that are not supported by evidence.

Acetaminophen is widely available and often used, given its presumed safety profile and low cost. Clinical guideline recommendations regarding its use are variable, and results from a network meta-analysis comparing various nonoperative treatments found acetaminophen to be one of the least efficacious treatment options (effect size $0.18,95 \% \mathrm{Cl}$ 0.04 to 0.33$).{ }^{64}$

Surgical management of the degenerative knee by means of arthroscopic lavage or debridement has been shown to have no clinical benefit compared with nonoperative treatments. ${ }^{65,66}$ In the case of mechanical symptoms in the absence of osteoarthritic changes in the joint, we suggest considering a referral to an orthopedic specialist for determination of whether arthroscopy is warranted.

\section{How do the various treatments compare?}

Comparative effectiveness was previously difficult to discern with traditional meta-analytic methods. Network meta-analysis, however, has allowed for multiple comparisons by using direct evidence from comparative studies as well as indirect evidence from comparisons of treatments with a common reference. ${ }^{67} \mathrm{~A}$ network meta-analysis of 137 RCTs compared the effectiveness of nonoperative treatments, including oral and intra-articular placebo, intra-articular corticosteroids and hyaluronic acid, as well as various oral pain medications. ${ }^{64}$ Oral naproxen, ibuprofen and diclofenac were superior to acetaminophen, and diclofenac had the greatest effect size of comparators taken orally. A critical finding from the study is that intra-articular treatment options (corticosteroids and hyaluronic acid) were more effective for pain relief than oral agents, with hyaluronic acid the most efficacious with respect to both pain and function (effect size $0.63,95 \%$ credible interval [ $\mathrm{Crl}] 0.39$ to 0.88 ). This analysis further clarified the placebo effect of an intra-articular injection and reported that none of the nonsteroidal anti-inflammatory drugs taken orally had treatment effects greater than an intraarticular placebo. ${ }^{64}$

Figure 1 shows a suggested algorithm for conservative management of knee osteoarthritis.

\section{What are the emerging therapies?}

The market for newer biological treatments for osteoarthritis is growing rapidly and corresponds to an exponential increase in the number of publications on such treatments.
More than 80 RCTs and 23 systematic reviews have evaluated platelet-rich plasma, with more than $30 \%$ of these published in the last two years. Platelet-rich plasma is autologous blood with supraphysiologic concentrations of platelets containing bioactive proteins and growth factors to promote the body's healing process. Use of platelet-rich plasma in knee osteoarthritis was evaluated in a recent meta-analysis of 10 RCTs, which found that intra-articular injection of plateletrich plasma was associated with significant improvements in pain and functional outcomes compared with hyaluronic acid or saline injections. ${ }^{68}$ However, there is substantial heterogeneity among RCTs with regard to platelet and leukocyte concentration, use of activating agents and growth factor concentrations, the role of which will need to be clarified by future research. Notwithstanding, the market for platelet-rich plasma is expected to surpass US\$451 million annually by 2024. ${ }^{69}$ Biological interventions such as platelet-rich plasma may play a larger role in managing the treatment of young patients with osteoarthritis. Future large RCTs are needed to answer critical questions regarding indications and composition of such treatments.

There is growing interest in the possibility of using stem cell- based treatments for knee osteoarthritis. A systematic review of randomized and observational studies concluded that although results from the available literature supported decreased pain scores and improved functional outcomes, no high level of evidence for stem cell therapy in the treatment of patients is currently available. ${ }^{70}$

Research into novel pathways for pain management and opioid avoidance continues with evaluating the potential role for cannabis-based medications. Future treatment options may also include biologic modulators of the Wnt pathway, which is implicated in the pathophysiology of osteoarthritis. Early clinical trials of such agents are underway, looking at whether they decrease or reverse the rate of cartilage breakdown (NCT03122860). ${ }^{71}$ Questions for future research are summarized in Box 2.

\section{What about a multimodal approach to treatment?}

Guidelines rarely recommend a multimodal approach to treatment, and treatment options are often presented according to best evidence or level of invasiveness, as if they should be used in sequence. In reality, patients often use many treatments in parallel. The additive, or synergistic, effects of multimodal therapies for knee osteoarthritis are largely unknown and understudied. Patients may meet with a number of physicians and allied health professionals when seeking care for osteoarthritic symptoms. We suggest that a multidisciplinary approach or comprehensive multimodal approach to managing symptoms of knee osteoarthritis through physical therapy, lifestyle modifications and pharmacologic treatments is most sensible. As guidelines are updated, clear comparative analyses of the relative value of single and multimodal approaches should be undertaken. 


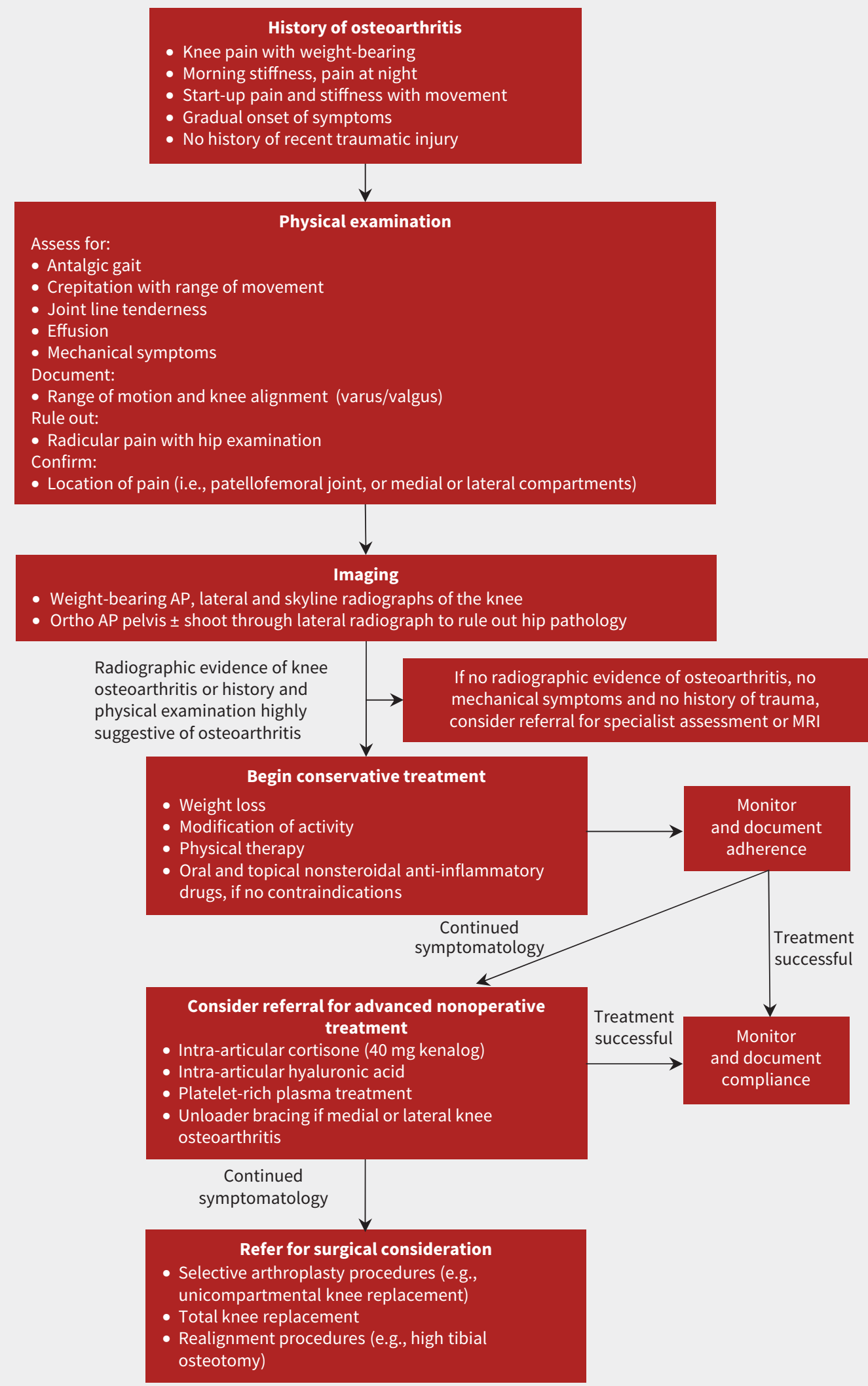

Figure 1: Suggested algorithm for conservative management of knee osteoarthritis. Note: AP = anteroposterior, MRI = magnetic resonance imaging. 


\section{Box 2: Unanswered questions}

- What is the comparative effectiveness of upcoming knee injectables?

- What specific formulation of platelet-rich plasma shows efficacy in knee osteoarthritis?

- What role do stem cell injections play in the knee?

- What is the comparative effectiveness of platelet-rich plasma and stem cells?

- What is the optimal combination treatment for knee osteoarthritis?

- What is the role of cannabinoids in knee osteoarthritis?

\section{References}

1. Woolf AD, Pfleger B. Burden of major musculoskeletal conditions. Bull World Health Organ 2003;81:646-56.

2. Chapter one: Life with arthritis in Canada: a personal and public health challenge What is arthritis and how common is it? Ottawa: Public Health Agency of Canada; 2010. Available: www.canada.ca/en/public-health/services/chronic-diseases/ arthritis/life-arthritis-canada-a-personal-public-health-challenge/chapter-one-what -is-arthritis-and-how-common-is-it.html (accessed 2017 Sept. 7).

3. Sharif B, Garner R, Hennessy D, et al. Productivity costs of work loss associated with osteoarthritis in Canada from 2010 to 2031. Osteoarthritis Cartilage 2017;25:249-58.

4. London NJ, Miller LE, Block JE. Clinical and economic consequences of the treatment gap in knee osteoarthritis management. Med Hypotheses 2011;76:887-92.

5. Altman RD, Schemitsch E, Bedi A. Assessment of clinical practice guideline methodology for the treatment of knee osteoarthritis with intra-articular hyaluronic acid. Semin Arthritis Rheum 2015;45:132-9.

6. Li CS, Karlsson J, Winemaker M, et al. Orthopedic surgeons feel that there is a treatment gap in management of early OA: international survey. Knee Surg Sports Traumatol Arthrosc 2014;22:363-78.

7. Witjes S, van Geenen RCl, Koenraadt KLM, et al. Expectations of younger patients concerning activities after knee arthroplasty: Are we asking the right questions? Qual Life Res 2017;26:403-17.

8. Haynes J, Sassoon A, Nam D, et al. Younger patients have less severe radiographic disease and lower reported outcome scores than older patients undergoing total knee arthroplasty. Knee 2017;24:663-9.

9. Bourne RB, Chesworth BM, Davis AM, et al. Patient satisfaction after total knee arthroplasty: Who is satisfied and who is not? Clin Orthop Relat Res 2010;468:57-63.

10. Parvizi J, Nunley RM, Berend KR, et al. High level of residual symptoms in young patients after total knee arthroplasty. Clin Orthop Relat Res 2014;472:133-7.

11. Ferket BS, Feldman Z, Zhou J, et al. Impact of total knee replacement practice: cost effectiveness analysis of data from the Osteoarthritis Initiative. BMJ 2017;356:j1131.

12. Culliford D, Maskell J, Judge A, et al. Future projections of total hip and knee arthroplasty in the UK: results from the UK Clinical Practice Research Datalink. Osteoarthritis Cartilage 2015;23:594-600.

13. Kurtz SM, Lau E, Ong K, et al. Future young patient demand for primary and revision joint replacement: national projections from 2010 to 2030. Clin Orthop Relat Res 2009;467:2606-12.

14. Bayliss LE, Culliford D, Monk AP, et al. The effect of patient age at intervention on risk of implant revision after total replacement of the hip or knee: a populationbased cohort study. Lancet 2017;389:1424-30.

15. Lübbeke A, Katz JN, Perneger TV, et al. Primary and revision hip arthroplasty: 5-year outcomes and influence of age and comorbidity. J Rheumatol 2007;34:394-400.

16. Messier SP, Gutekunst DJ, Davis C, et al. Weight loss reduces knee-joint loads in overweight and obese older adults with knee osteoarthritis. Arthritis Rheum 2005;52:2026-32.

17. Fransen M, McConnell S, Harmer AR, et al. Exercise for osteoarthritis of the knee. Cochrane Database Syst Rev 2015;(1):CD004376.

18. Messier SP, Loeser RF, Miller GD, et al. Exercise and dietary weight loss in overweight and obese older adults with knee osteoarthritis: the arthritis, diet, and activity promotion trial. Arthritis Rheum 2004;50:1501-10.

19. Hunter DJ, Eckstein F. Exercise and osteoarthritis. J Anat 2009;214:197-207.

20. Phillips S, Silvia Li C, Phillips M, et al. Treatment of osteoarthritis of the knee with bracing: a scoping review. Orthop Rev (Pavia) 2016;8:6256.

21. Moyer RF, Birmingham TB, Bryant DM, et al. Valgus bracing for knee osteoarthritis: a meta-analysis of randomized trials. Arthritis Care Res (Hoboken) 2015;67:493-501.

22. Segal NA, Glass NA, Felson DT, et al. Effect of quadriceps strength and proprioception on risk for knee osteoarthritis. Med Sci Sports Exerc 2010;42:2081-8.
23. Brosseau L, Taki J, Desjardins B, et al. The Ottawa panel clinical practice guidelines for the management of knee osteoarthritis. Part two: strengthening exercise programs. Clin Rehabil 2017;31:596-611.

24. Gore M, Tai K-S, Sadosky A, et al. Use and costs of prescription medications and alternative treatments in patients with osteoarthritis and chronic low back pain in community-based settings. Pain Pract 2012;12:550-60.

25. da Costa BR, Reichenbach S, Keller N, et al. Effectiveness of non-steroidal antiinflammatory drugs for the treatment of pain in knee and hip osteoarthritis: a network meta-analysis. Lancet 2017;390:e21-33.

26. Garcia Rodríguez LA, Hernández-Díaz S. The risk of upper gastrointestinal complications associated with nonsteroidal anti-inflammatory drugs, glucocorticoids, acetaminophen, and combinations of these agents. Arthritis Res 2001;3:98-101.

27. Coxib and traditional NSAID Trialists' (CNT) Collaboration; Bhala N, Emberson J, Merhi A, et al. Vascular and upper gastrointestinal effects of non-steroidal antiinflammatory drugs: meta-analyses of individual participant data from randomised trials. Lancet 2013;382:769-79.

28. Rannou F, Pelletier J-P, Martel-Pelletier J. Efficacy and safety of topical NSAIDs in the management of osteoarthritis: evidence from real-life setting trials and surveys. Semin Arthritis Rheum 2016;45(Suppl 4):S18-21.

29. Sardana V, Burzynski J, Zalzal P. Safety and efficacy of topical ketoprofen in transfersome gel in knee osteoarthritis: a systematic review. Musculoskeletal Care 2017;15:114-21.

30. Derry S, Conaghan P, Da Silva JAP, et al. Topical NSAIDs for chronic musculoskeletal pain in adults. Cochrane Database Syst Rev 2016;(4):CD007400.

31. Chou R, McDonagh MS, Nakamoto E, et al. Analgesics for osteoarthritis: an update of the 2006 Comparative Effectiveness Review. In: Comparative Effectiveness Reviews, No. 38. Rockville (MD): Agency for Healthcare Research and Quality; 2011. Available: www.ncbi.nlm.nih.gov/books/NBK65646/ (accessed 2017 Sept. 14).

32. Smith SR, Deshpande BR, Collins JE, et al. Comparative pain reduction of oral non-steroidal anti-inflammatory drugs and opioids for knee osteoarthritis: systematic analytic review. Osteoarthritis Cartilage 2016;24:962-72.

33. Johal H, Devji T, Schemitsch EH, et al. Viscosupplementation in knee osteoarthritis: evidence revisited. JBJS Rev 2016;4:e11-111.

34. Jordan KM, Arden NK, Doherty M, et al. EULAR Recommendations 2003: an evidence based approach to the management of knee osteoarthritis: report of a task force of the Standing Committee for International Clinical Studies Including Therapeutic Trials (ESCISIT). Ann Rheum Dis 2003;62:1145-55.

35. Hochberg MC, Altman RD, April KT, et al. American College of Rheumatology 2012 recommendations for the use of nonpharmacologic and pharmacologic therapies in osteoarthritis of the hand, hip, and knee. Arthritis Care Res (Hoboken) 2012; 64:465-74.

36. Treatment of osteoarthritis of the knee: evidence-based guideline (2nd edition) [guideline]. Rosemont (IL): American Academy of Orthopaedic Surgeons; 2013. Available: www.orthoguidelines.org/topic?id=1005(accessed 2017 May 16).

37. Osteoarthritis: care and management. London: National Institute for Health and Care Excellence; 2013. Available: www.nice.org.uk/guidance/CG177 (accessed 2017 May 16).

38. McAlindon TE, Bannuru RR, Sullivan MC, et al. OARSI guidelines for the non-surgical management of knee osteoarthritis. Osteoarthritis Cartilage 2014;22:363-88.

39. Busse JW, Craigie S, Juurlink DN, et al. Guideline for opioid therapy and chronic noncancer pain. CMAJ 2017;189:E659-66.

40. de Campos GC, Rezende MU, Pailo AF, et al. Adding triamcinolone improves viscosupplementation: a randomized clinical trial. Clin Orthop Relat Res 2013;471:613-20.

41. Kosinska MK, Ludwig TE, Liebisch G, et al. Articular joint lubricants during osteoarthritis and rheumatoid arthritis display altered levels and molecular species. PLOS One 2015;10:e0125192.

42. Strauss EJ, Hart JA, Miller MD, et al. Hyaluronic acid viscosupplementation and osteoarthritis: current uses and future directions. Am J Sports Med 2009;37:1636-44.

43. Rutjes AWS, Jüni $P$, da Costa BR, et al. Viscosupplementation for osteoarthritis of the knee: a systematic review and meta-analysis. Ann Intern Med 2012;157:180-91.

44. Bellamy N, Campbell J, Robinson V, et al. Viscosupplementation for the treatment of osteoarthritis of the knee. Cochrane Database Syst Rev 2006;(2):CD005321.

45. Altman RD, Bedi A, Karlsson J, et al. Product differences in intra-articular hyaluronic acids for osteoarthritis of the knee. Am J Sports Med 2016;44:2158-65.

46. Jüni P, Hari R, Rutjes AWS, et al. Intra-articular corticosteroid for knee osteoarthritis. Cochrane Database Syst Rev 2015; (10):CD005328.

47. da Costa BR, Hari R, Jüni P. Intra-articular corticosteroids for osteoarthritis of the knee. JAMA 2016;316:2671-2.

48. McAlindon TE, LaValley MP, Harvey WF, et al. Effect of intra-articular triamcinolone vs saline on knee cartilage volume and pain in patients with knee osteoarthritis: a randomized clinical trial. JAMA 2017;317:1967-75.

49. Lana JFSD, Weglein A, Sampson SE, et al. Randomized controlled trial comparing hyaluronic acid, platelet-rich plasma and the combination of both in the treatment of mild and moderate osteoarthritis of the knee. J Stem Cells Regen Med 2016;12:69-78. 
50. Saturveithan C, Premganesh G, Fakhrizzaki S, et al. Intra-articular hyaluronic acid (HA) and platelet rich plasma (PRP) injection versus hyaluronic acid (HA) injection alone in patients with grade III and IV knee osteoarthritis (OA): a retrospective study on functional outcome. Malays Orthop J 2016;10:35-40.

51. Brouwer RW, Huizinga MR, Duivenvoorden T, et al. Osteotomy for treating knee osteoarthritis. Cochrane Database Syst Rev 2014;(12):CD004019.

52. Niinimäki TT, Eskelinen A, Mann BS, et al. Survivorship of high tibial osteotomy in the treatment of osteoarthritis of the knee: Finnish registry-based study of 3195 knees. J Bone Joint Surg Br 2012;94:1517-21.

53. Ramappa M, Anand S, Jennings A. Total knee replacement following high tibial osteotomy versus total knee replacement without high tibial osteotomy: a systematic review and meta analysis. Arch Orthop Trauma Surg 2013;133:1587-93.

54. W-Dahl A. Robertsson O, Lidgren L, et al. Unicompartmental knee arthroplasty in patients aged less than 65. Acta Orthop 2010;81:90-4.

55. Mohammad HR, Strickland L, Hamilton TW, et al. Long-term outcomes of over 8000 medial Oxford Phase 3 Unicompartmental Knees - a systematic review. Acta Orthop 2017 Aug. 23 [Epub ahead of print]. doi:10.1080/17453674.2017.1367577.

56. Witjes S, Gouttebarge V, Kuijer PPFM, et al. Return to sports and physical activity after total and unicondylar knee arthroplasty: a systematic review and meta-analysis. Sports Med 2016;46:269-92.

57. Siddiqui NA, Ahmad ZM. Revision of unicondylar to total knee arthroplasty: a systematic review. Open Orthop J 2012;6:268-75.

58. Skou ST, Roos EM, Laursen MB, et al. A randomized, controlled trial of total knee replacement. N Engl J Med 2015;373:1597-606.

59. Losina E, Katz JN. Total knee arthroplasty on the rise in younger patients: Are we sure that past performance will guarantee future success? Arthritis Rheum 2012; 64:339-41.

60. Franceschetti E, Torre G, Palumbo A, et al. No difference between cemented and cementless total knee arthroplasty in young patients: a review of the evidence. Knee Surg Sports Traumatol Arthrosc 2017;25:1749-56.

61. Reginster J-Y, Dudler J, Blicharski T, et al. Pharmaceutical-grade Chondroitin sulfate is as effective as celecoxib and superior to placebo in symptomatic knee osteoarthritis: the ChONdroitin versus CElecoxib versus Placebo Trial (CONCEPT). Ann Rheum Dis 2017;76:1537-43.
62. Hinman RS, Crossley KM, McConnell J, et al. Efficacy of knee tape in the management of osteoarthritis of the knee: blinded randomised controlled trial. BMJ 2003;327:135.

63. Parkes MJ, Maricar N, Lunt M, et al. Lateral wedge insoles as a conservative treatment for pain in patients with medial knee osteoarthritis: a meta-analysis. JAMA 2013;310:722-30.

64. Bannuru RR, Schmid CH, Kent DM, et al. Comparative effectiveness of pharmacologic interventions for knee osteoarthritis: a systematic review and network metaanalysis. Ann Intern Med 2015;162:46-54.

65. Khan M, Evaniew N, Bedi A, et al. Arthroscopic surgery for degenerative tears of the meniscus: a systematic review and meta-analysis. CMAJ 2014;186:1057-64.

66. Thorlund JB, Juhl CB, Roos EM, et al. Arthroscopic surgery for degenerative knee: systematic review and meta-analysis of benefits and harms. BMJ 2015;350:h2747.

67. Mills EJ, Thorlund K, loannidis JPA. Demystifying trial networks and network meta-analysis. BMJ 2013;346:f2914.

68. Dai W-L, Zhou A-G, Zhang H, et al. Efficacy of platelet-rich plasma in the treatment of knee osteoarthritis: a meta-analysis of randomized controlled trials. Arthroscopy 2017;33:659-70.e1.

69. Platelet rich plasma (PRP) market (type - pure-platelet rich plasma (P-PRP), leukocyte-platelet rich plasma (L-PRP), and pure-platelet-rich fibrin (P-PRF); Origin - autologous, homologous, and allogeneic; Application - orthopedic surgery, neurosurgery, cosmetic surgery, general surgery, urological surgery, cardiothoracic surgery, and periodontal surgery) - global industry analysis, size, share, growth, trends and forecast 2016-2024. Transparency Market Research 2016 Nov. 24. Available: www.transparencymarketresearch.com/platelet-rich -plasma-market.html (accessed 2016 Dec. 6).

70. Pas HI, Winters M, Haisma HJ, et al. Stem cell injections in knee osteoarthritis: a systematic review of the literature. Br J Sports Med 2017;51:1125-33.

71. Yazici Y. A study evaluating the safety and efficacy of SM04690 for the treatment of moderately to severely symptomatic knee osteoarthritis. ClinicalTrials.gov: NCT03122860. Available: https://clinicaltrials.gov/ct2/show/NCT03122860?term= A+Study+Evaluating+the+Safety+and+Efficacy+of+SM04690+for+the+Treatment+ of+Moderately+to+Severely+Symptomatic+Knee+Osteoarthritis\&rank=1 (accessed 2017 Sept. 20).
Competing interests: Mohit Bhandari reports research grants from Sanofi, Pendopharm, Ferring and DJO, outside the submitted work. Mitchell Winemaker reports personal fees and nonfinancial support from Stryker Canada, outside the submitted work. No other competing interests were declared.
This article has been peer reviewed.

Affiliation: Division of Orthopaedic Surgery, McMaster University, Hamilton, Ont.

Contributors: All of the authors contributed to the conception and design of the work, drafted the manuscript, revised it critically for important intellectual content, gave final approval of the version to be published and agreed to be accountable for all aspects of the work.

Correspondence to: Moin Khan, khanmm2@mcmaster.ca 